\title{
A Head-Space Method for Measuring Activity Coefficients, Partition Coefficients, and Solubilities of Hydrocarbons in Saline Solutions
}

\author{
Stanley P. Wasik, Frederick P. Schwarz, Yadu B. Tewari, and Michele M. Miller \\ National Bureau of Standards, Gaithersburg, MD 20899 \\ and \\ J. H. Purnell \\ University College of Swansea, Swansea, Wales, UK
}

\begin{abstract}
Accepted: February 2, 1984
An apparatus is described which measures the equilibrium distribution of a hydrocarbon between a gas and aqueous phase. Soluble hydrocarbons are extracted from an aqueous salt solution by very small bubbles of hydrogen generated electrolytically from a gold electrode located at the bottom of a cylindrical cell. The partition coefficient is determined from the volume of the aqueous solution and the solute concentration in the head-space after a measured volume of hydrogen has bubbled through the cell. The concentration of the solute in the head-space is measured by gas chromatography. The observed distribution is supplemented by vapor pressure and molar volume data and can be used to calculate the solubility and the activity coefficient of the solute in the aqueous phase. The partition coefficient, activity coefficient, and solubility for 18 alkylbenzenes in aqueous $0.5 \mathrm{M} \mathrm{NaCl}$ at $25^{\circ} \mathrm{C}$ were measured by this method.
\end{abstract}

Key words: activity coefficient; aqueous solubility; head-space; partition coefficient.

\section{Introduction}

A knowledge of the equilibrium properties of aqueous hydrocarbon solutions is valuable in several fields. In water pollution control, such information is helpful in devising abatement processes $[1]^{1}$, in modeling natural water systems [2], in designing toxicity experiments, and in developing analytical methods. In petroleum re-

\begin{abstract}
About the Authors: Stanley P. Wasik, who like his fellow NBS authors is a research chemist in the Bureau's Center for Chemical Physics, did some of the work reported on here while on sabbatical leave at the University College of Swansea where J. H. Purnell is a professor of chemistry and a researcher.
\end{abstract}

\footnotetext{
' Figures in brackets indicate literature references at the end of this paper.
}

search, it is useful for understanding how hydrocarbons migrate and accumulate to form oil deposits [3]. In biology, a knowledge of how hydrocarbons behave in aqueous solutions is important for understanding the effects of hydration on the configuration of biopolymers [4]. In chemistry, experimental data on these systems are needed for testing models of water and aqueous solu* tions [5].

These aqueous solutions can be characterized by determining the concentration of a particular hydrocarbon in both the solution and the vapor in equilibrium with solution. The ratio of the solute concentration in the two phases is a stoichiometric equilibrium constant, commonly called the partition coefficient, $K$. The solubility may be determined from the value of $K$ and the solute saturation vapor pressure. Another thermodynamic property of interest is the solute activity coefficient based on volume fraction, $\gamma_{\phi}$, which may be calculated 
from the value of $K$, the solute molar volume, and the solute saturation vapor pressure. This property is of particular importance in developing correlations based on some additive property of the solute, such as molar volume or carbon number, since $\gamma_{\phi}$ depends only weakly on temperature and varies significantly less with solute structure and configuration than does the corresponding correlation with solubilities or with the mole fractiondefined activity coefficient, $\gamma_{x}$.

We have previously described a method for measuring $K$ using a head-space technique $[6,7,8]$ which is best suited for measuring $K$ in the range $1-10$. We now report a method without limitations on the value of $K$. In this method, the soluble hydrocarbons are extracted from aqueous salt solutions by very small bubbles of hydrogen generated electrolytically from a gold electrode located at the bottom of a cylindrical cell. The partition coefficient is determined from the volume of aqueous solution and the solute concentration in the head-space after a measured volume of hydrogen has bubbled through the cell. The concentration of the hydrocarbon in the head-space is analytically determined by conventional gas chromatography. The partition coefficients, solubilities, and activity coefficients for 18 alkylbenzenes in aqueous $0.5 \mathrm{M} \mathrm{NaCl}$ at $25^{\circ} \mathrm{C}$ measured by this method are reported here.

\section{Experimental}

Figure 1 shows the extraction cell. The compartments $A$ and $B$ have internal volumes of 50 and $40 \mathrm{ml}$, respectively. The two compartments are connected by means of a $14 \mathrm{~mm}$ o.d. glass tube with a $10 \mathrm{~mm}$ o.d. coarse porosity glass frit on one end. A silicic acid plug is precipitated on the compartment $B$ side of the frit to prevent the flow of liquid from one compartment to another and to provide low resistance for the flow of electric current. The gold electrode (1 mm o.d. wire) in compartment $\mathrm{A}$ is positioned by means of a septum held in a $1 / 4 \times 1 / 4$ in union fitting. This electrode has a spiral configuration to provide a large surface area. The electrode in compartment $B$ is a straight segment of $1 \mathrm{~mm}$ o.d. platinum wire.

The extraction cell is immersed in a bath controlled to $\pm 0.02{ }^{\circ} \mathrm{C}$. The thermometer used in this work was calibrated with an accuracy of $\pm 0.01{ }^{\circ} \mathrm{C}$ by the National Bureau of Standards. The head-space is sampled by a gas injection valve thermostated at $150^{\circ} \mathrm{C}$. The $1 / 8$ in o.d. stainless steel tube connecting the extraction cell with the valve is heated to $150^{\circ} \mathrm{C}$ by a heating tape.

The chromatographic column is a $15 \mathrm{~m} \times 0.5 \mathrm{~mm}$ i.d. SCOT column prepared with finely ground di-

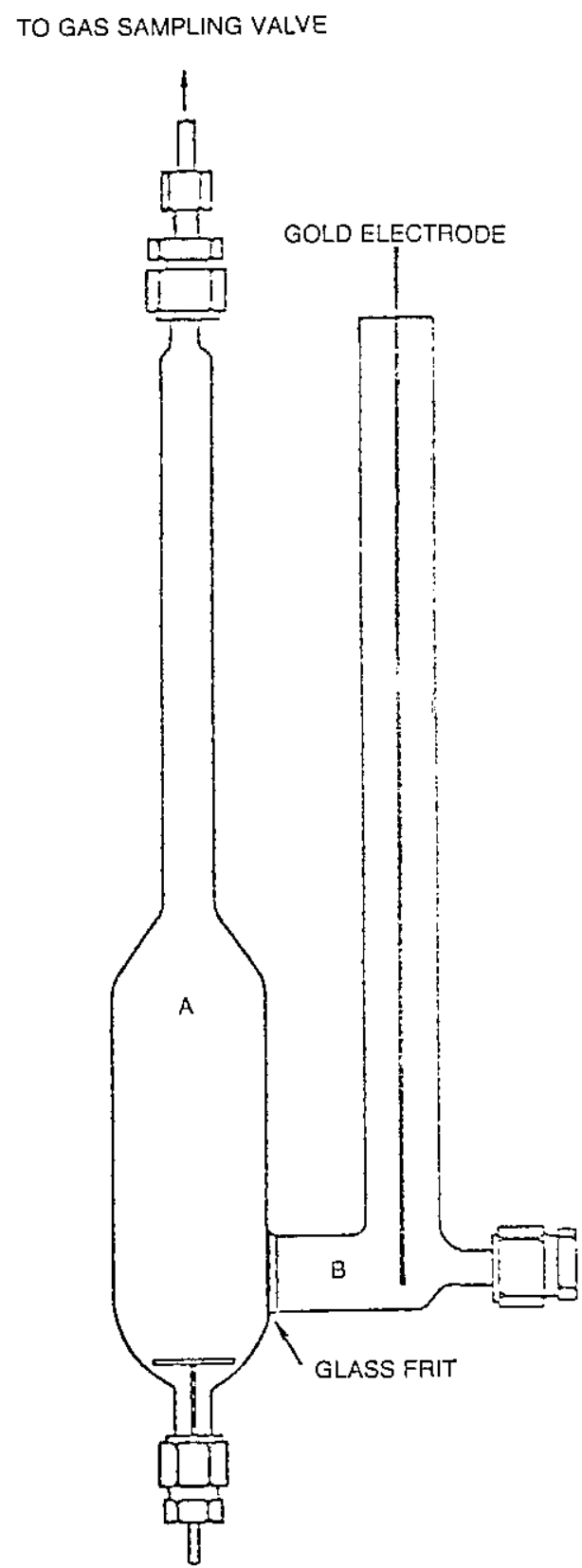

GOLD ELECTRODE

Figure 1-Extraction cell compartments $\mathrm{A}$ and $\mathrm{B}$ have internal volumes of 50 and $40 \mathrm{ml}$, respectively.

atomaceous earth on a fused silica support and coated with a mixture of $\mathrm{m}$-bis(m-phenoxy phenyl) benzene and Apiezon L. The effluent is monitored by a hydrogen flame detector with an electronic integrator measuring peak areas. 
A constant current power supply with a stability of $1 / 10,000$ provides electrical current to the extraction cell. The volume of hydrogen plus water vapor, $V$, bubbled through compartment $\mathrm{A}$ is calculated from the equation

$$
V=(i t / 2 F)\left[R T /\left(p_{\mathrm{A}}-p_{w}\right)\right]
$$

where $i$ is current; $t$, the time in seconds; $F$, the Faraday constant; $R$, the gas constant; $p_{\mathrm{A}}$, the atmospheric pressure; and $p_{w}$, the vapor pressure of the aqueous solution at temperature $T(\mathrm{~K})$.

The aromatic hydrocarbons used in this study had a stated purity of 99.9 mole \%. The water used in the preparation of solutions was doubly distilled over potassium permanganate.

\section{Procedure}

A mixture of several of the alkylbenzenes was prepared such that their partial pressures at $25{ }^{\circ} \mathrm{C}$ were approximately the same. Five $\mathrm{ml}$ of the mixture was gently stirred with $100 \mathrm{ml}$ of aqueous $0.5 \mathrm{M} \mathrm{NaCl}$ for 2 $\mathrm{h}$ and then allowed to stand overnight. Compartment $\mathrm{A}$ was filled with the aqueous solution leaving only a small volume of head-space $(<1.0 \mathrm{ml})$ above the solution. The volume of the solution was determined from the weight of the cell before and after filling and from the density of the solution. Compartment $B$ was filled to the same level as compartment $\mathrm{A}$ with $5 \% \mathrm{v} / \mathrm{v} \mathrm{H}_{2} \mathrm{SO}_{4}$ solution. The extraction cell was then immersed in the constant temperature bath for $1 \mathrm{~h}$ before electric current $(0.2-0.4$ amp) was passed through the cell. A small volume of the head-space $(0.3 \mathrm{~mL})$ was injected into the gas chromatograph via the gas sampling valve for analysis. The alkylbenzenes were chosen so that there was a baseline separation for each peak. The peak areas were recorded along with the time of sample injection. This procedure was repeated every $10 \mathrm{~min}$ until the peak areas were approximately $1 / 100$ their original value.

In order to measure the peak area corresponding to the solute saturation vapor pressure three columns were constructed of stainless steel tubing, $2.5 \mathrm{~mm}$ i.d. and 0.5 $m$ in length. The solid support was Chromosorb W (60-80 mesh) with toluene, ethylbenzene, and npropylbenzene as the stationary phase, respectively. Each column was immersed in the constant temperature bath, and helium saturated with water vapor was allowed to flow through it before being sampled for analysis.

\section{Thermodynamic Background}

Consider a known volume, $V_{\mathrm{L}}$, of aqueous salt solution of hydrocarbons in a cylindrical vessel containing a gold electrode at the bottom. Connected to this vessel by means of a glass fritted disc is another vessel containing an aqueous solution of $\mathrm{H}_{2} \mathrm{SO}_{4}$. When electric current with the appropriated polarity passes through the cell, hydrogen in the form of very small bubbles is evolved at the electrode in the vessel containing the aqueous solution, and oxygen is evolved at the other electrode. Water vapor and the dissolved hydrocarbons in the aqueous solution are equilibrated with the hydrogen bubbles. The hydrocarbon concentrations in the head-space are measured by means of gas chromatography. We may assume that the concentration of a particular hydrocarbon in the head-space is proportional to its concentration in the aqueous solution. One then has the relationship

$$
C_{w i}(v)=K_{i} C_{h i}(v)
$$

where $C_{w i}(v)$ and $C_{h i}(v)$ are the concentrations of the $i^{\text {th }}$ hydrocarbon in the aqueous solution and in the headspace, respectively, after a volume $V$ of hydrogen plus water vapor has bubbled through the cell and $K_{i}$ is the proportionality factor. Under equilibrium conditions $K_{i}$ would be the partition coefficient. Conservation of mass requires that the ratio of $C_{h i}(V)$, corresponding to the passage of volume $V$, to its value, $C_{h i}(0)$, at zero hydrogen volume is given by the expession

$$
\ln \left[C_{h i}(V) / C_{h i}(0)\right]=-V /\left(V_{L} K_{i}\right)
$$

The peak area for the $i^{\text {th }}$ hydrocarbon, $A_{i}(V)$ may be expressed as

$$
A_{i}(V)=\sigma_{i} C_{h i}(V) V_{s}
$$

where $\sigma_{i}$ is the instrument sensitivity constant for the $i^{\text {th }}$ hydrocarbon and $V_{s}$ is the volume of the gas sampling valve sample loop. Substituting for $C_{h i}(V)$ in eq (3),

$$
\ln \left[A_{i}(V) / A_{i}(0)\right]=-V / V_{L} K_{i} .
$$

A plot of $\ln A_{i}(V)$ versus $V$ (or time) should thus be linear if $K_{i}$ is constant, and the slope will give the value of $K_{i}$.

The attainment of equilibrium of the dissolved hydrocarbons in the aqueous solution with the hydrogen bub- 
bles depends on the size of the bubbles and the contact time. Hydrogen bubbles generated electrolytically are less than $0.1 \mathrm{~mm}$ in diameter. Under these conditions the bubbles are small enough and the contact time with the solution long enough that equilibrium would be expected before the bubbles reached the surface, and the measured $K_{i}$ should be the partition coefficient.

During the course of the measurements water is continually being removed from the generating cell as saturated water vapor. For measurements near room temperature the amount of water removed is very small $(<0.1 \%)$; hence, no corrections are made for this effect.

\section{Activity Coefficient}

The partition coefficient $K_{i}$ may be defined as

$$
K_{i}=\frac{C_{w i}(\mathrm{v})}{C_{h i}(v)}=\left(\frac{n_{i}}{V_{L}}\right) \frac{R T}{P_{i}}
$$

where $n_{l}$ is the number of moles of the $i^{\text {th }}$ hydrocarbon, $P_{i}$ is the partial pressure of hydrocarbon at temperature $T, R$ is the gas constant, and $V_{L}$ is the total volume of aqueous solution. The partial pressure $\left(P_{i}\right)$ may be expressed in terms of volume fraction-based activity coefficient $\left(\gamma_{\phi i}\right)$ as

$$
P_{i}=\gamma_{\phi i} \phi_{i} P_{l}^{o}
$$

where $P_{i}^{o}$ is the saturated vapor pressure of the solute and $\phi_{i}$ is the solute volume fraction combining eqs (6) and (7) we get

$$
K_{i}=\frac{R T}{\gamma_{\phi i} V_{i} P_{i}^{o}}
$$

where $V_{i}$ is the molar volume of the $i^{\text {th }}$ hydrocarbon at temperature $T$.

\section{Solubility}

In order to calculate the hydrocarbon aqueous solubility from $K$ vialues, it is essential that the hydrocarbon concentration in the aqueous phase be proportional to its concentration in the gas phase, $P_{l} / R T$, up to the solute saturation vapor pressure, $p_{i}^{o}$, i.e., a two-phase system, liquid solute and aqueous solution saturated with solute. Under these conditions

$$
K=C_{w}^{o} R T / p^{o}
$$

where $C_{w}^{o}$ is the solubility of the solute temperature $T$. When liquid hydrocarbon is present at equilibrium with an aqueous phase, it will dissolve some water. The amount of water dissolved is so small, however (the solubility of water in all hydrocarbons at $25^{\circ} \mathrm{C}$ is well under $x=0.01$ ) that no correction need be made for its effect on the hydrocarbon's vapor pressure.

\section{Results and Discussion}

Ln $A(V)$ versus $V$ plots (eq (5)) for some alkylbenzenes in which the initial aqueous solution was saturated with the solute indicate that the proportionality between solute concentration in the gas phase and aqueous phase holds up to the solute saturation concentration in the aqueous phase (solubility) and that eq (9) may be used to calculate solubilities for these compounds. Values for $\ln A_{i}(0)$ (time equal to zero) were obtained from the saturation vapor pressure at $25^{\circ} \mathrm{C}$ using pure solute.

The partition coefficients were calculated from the slopes of the $\ln A_{i}(V)$ versus $V$ plots for the alkylbenzenes. These values are given in table 1 along with values of the solute activity coefficients calculated via eq (8). For comparison, values of the solute activity coefficients calculated from solubility data measured using the generator column method [10] are given in the same table. The good agreement between the two sets of data justifies the assumption made in deriving eq (7), i.e., $\gamma_{\phi} \neq 1$ for an apolar solute in equilibrium with an aqueous phase.

The head-space method proposed in this paper may be used to measure $K$ for any type of compound. The largest error in the measurements comes from measuring peak areas. Since one needs to know the peak area at time $t$, as well as the peak area corresponding to the saturation vapor pressure, the average error in the partition coefficients is approximately $1.5 \%$.

The method has a disadvantage in that $K$ can be measured only in salt solutions since some electrolyte is required in the solution to conduct the electrical current. In order to determine $K$ in pure water, $K$ must be measured in salt solutions of differing concentration, $C_{s}$, and then extrapolated to zero salt concentration using Setchenow's expression

$$
\log \left(K^{w} / K^{s w}\right)=k_{s} C_{s}
$$

where $K^{w}$ is the solute partition coefficient in water, $K^{s w}$ is the solute partition coefficient in salt water of concentration $C_{s}$, and $k_{s}$ is the salting-out coefficient. 
Table 1. Partition coefficients, solubilities and activity coefficients for alkylbenzenes in aqueous $0.5 \mathrm{M} \mathrm{NaCl}$ at $25.0{ }^{\circ} \mathrm{C}$.

\begin{tabular}{|c|c|c|c|c|c|}
\hline Solutes & $\begin{array}{c}P_{2} \\
(\mathrm{~mm})\end{array}$ & $\begin{array}{c}V_{i} \\
(\mathrm{~mL} / \text { mole })\end{array}$ & $K_{a / w}$ & $\begin{array}{c}C_{s}^{w} \times 10^{3} \\
(\mathrm{M})\end{array}$ & $\log \gamma_{\phi}$ \\
\hline Benzene & 95.18 & 89.4 & $3.47 \pm 0.03$ & 17.76 & 2.799 \\
\hline Toluene & 28.45 & 106.9 & $2.74 \pm 0.02$ & 4.19 & $3.349(3.292)^{1}$ \\
\hline Ethylbenzene & 9.51 & 123.1 & $2.19 \pm 0.02$ & 1.12 & $3.861(3.809)$ \\
\hline 1,2-Dimethylbenzene & 6.62 & 121.2 & $3.52 \pm 0.02$ & 1.25 & $3.820(3.735)$ \\
\hline 1,4-Dimethylbenzene & 8.84 & 123.9 & $2.24 \pm 0.02$ & 1.06 & 3.882 \\
\hline n-Propylbenzene & 3.43 & 140.1 & $1.53 \pm 0.01$ & 0.282 & $4.403(4.419)$ \\
\hline Isopropylbenzene & 4.64 & 140.2 & $1.20 \pm 0.001$ & 0.299 & $4.378(4.260)$ \\
\hline 1,3,5-Trimethylbenzene & 2.61 & 139.6 & $2.01 \pm 0.01$ & 0.282 & 4,405 \\
\hline $1,2,4$-Trimethylbenzene & 2.096 & 137.9 & $2.78 \pm 0.02$ & 0.313 & 4.365 \\
\hline 2-Ethyl-1-Methylbenzene & 2.521 & 137.1 & $2.66 \pm 0.02$ & 0.361 & 4.305 \\
\hline 3-Ethyl-1-Methylbenzene & 2.999 & 139.7 & $1.69 \pm 0.02$ & 0.273 & 4.419 \\
\hline n-Butylbenzene & 1.011 & 156.8 & $1.18 \pm 0.01$ & 0.0642 & $4.997(4.952)$ \\
\hline Isobutylbenzene & 1.929 & 158.1 & $0.677 \pm 0.01$ & 0.0702 & 4.955 \\
\hline sec-Butylbenzene & $1.873^{\circ}$ & 156.4 & $0.870 \pm 0.01$ & 0.0876 & 4.863 \\
\hline t-Butylbenzene & 2.208 & 155.6 & $1.13 \pm 0.01$ & 0.134 & 4.681 \\
\hline 1,3-Diethylbenzene & 1.134 & 156.1 & $1.22 \pm 0.01$ & 0.0744 & 4.935 \\
\hline 1,2-Diethylbenzene & 1.043 & 153.2 & $1.81 \pm 0.02$ & 0.1015 & 4.794 \\
\hline 1,4-Diethylbenzene & 1.051 & 156.4 & $1.26 \pm 0.01$ & 0.0712 & 4.953 \\
\hline
\end{tabular}

\footnotetext{
${ }^{1}$ The values in brackets are calculated from experimental solubility data using the equation $\gamma_{\phi}=\left(C_{s}^{w} V_{l}\right)^{-1}$ where $V_{j}$ is the molar volume of
} the solute [10].

\section{References}

[1] Tsonopoulos, C. and J. M. Prausnitz. Activity coefficients of aromatic solutes in dilute aqueous solutions. Ind. Eng. Fundam. 10 (4): 493-600; 1971.

[2] LeFeurre, A. R. Water and Water Pollution Handbook, Vol. 1; Ciaccio, L. L., editor. New York: Marcel Dekker, Inc.; 1971. 263.

[3] Peake, E., and G. W. Hodgson. Alkanes in aqueous systems. I. Exploratory investigations on the accommodation of $\mathrm{C}_{20}-\mathrm{C}_{33} \mathrm{n}$-alkanes in distilled water and occurrence in natural water systems. J. Am. Oil Chemists Soc. 4: 215-222; 1966.

[4] Ben-Naim, A. Statistical mechanical study of hydrophobic interactions. III. Generalization and further applications, J. Chem. Phys. 57 (12): 5257-5265; 1972.

[5] Ben-Naim, A. Water and Aqueous Solutions; Horne, R. A., editor. New York: Wiley; 1972. 452.
[6] Wasik, S. P.; R. L. Brown, and J. I. Minor, Jr. Partition coefficients and solubility measurements of dimethylmercury in fresh and sea water over a temperature range $0-25{ }^{\circ}$ C. J. Environ Sci. Health. A11 (1): 99-105; 1976.

[7] Brown, R L., and S. P. Wasik. A method of measuring the solubilities of hydrocarbons in aqueous solutions. NBS J. Res. 78A (4): 453-460; 1974.

[8] Wasik, S. P. Partition of organoelements in octanol/water/air systems, Chap. 19 in Organometals and Organometalloids; Brinckman, F. E. and J. M. Bellama, editors. Washington, DC: ACS; 1978; 314-326.

[9] Wasik, S. P.; Y. B. Tewari, M. M. Miller, and J. H. Purnell. Measurements of the octanol/water partition coefficient by chromatographic methods. NBS J. Res. 87 (4): $311-315$; 1982.

[10] Tewari, Y. B.; M. M. Miller, S. P. Wasik, and D. E. Martire. Aqueous solubilities and octanol/water partition coefficient of organic compounds at $25.0^{\circ} \mathrm{C}$. J. Chem. Eng. Data. 27 (4): $451-454 ; 1982$. 